\title{
Gingko biloba Extract Ameliorates Colonic Inflammation in DSS-induced Model of Colitis in Mice
}

\author{
Ki-Jong Rhee ${ }^{1}$, Sun-Yeong Gwon ${ }^{1}$, Soonjae Hwang ${ }^{1}$, Chang Gun Lee ${ }^{1}$, \\ In-Ho Jang ${ }^{2}$, Myung-Bok Wie ${ }^{3}$ and Bae Dong Jung ${ }^{3, \dagger}$ \\ ${ }^{1}$ Department of Biomedical Laboratory Science, College of Health Sciences, Yonsei University, \\ Wonju, Gangwon-do 220-710, Korea, \\ ${ }^{2}$ Department of Biomedical Laboratory Science, College of Health Sciences, Sangji University, \\ Wonju, Gangwon-do 220-702, Korea, \\ ${ }^{3}$ College of Veterinary Medicine \& Institute of Veterinary Science, Kangwon National University, \\ Chuncheon, Gangwon-do 200-701, Korea
}

\begin{abstract}
Ulcerative colitis (UC) is a serious gastrointestinal tract disease characterized by recurrent chronic inflammation and mucosal damage of the gastrointestinal tract. The conventional therapies of choice are anti-inflammatory agents, steroids and anti-TNF- $\alpha$ therapy. However, inherent limitations in these therapies have steered many UC patients to supplement existing therapies with alternative medicinal products. In the current study, we tested the efficacy of Gingko bilola extract (EGb 761) in abating colonic inflammation in a DSS-induced murine model of colitis. C57BL/6 mice were administered $2 \%$ DSS in the drinking water for 7 days, then regular water for 7 days, and then $2 \%$ DSS for an additional 7 days. EGb $761(1 \mathrm{mg} /$ dose $)$ was oral gavaged daily for the duration of the experiment. At the termination of the experiment, mice treated with EGb+DSS showed higher body weight, lower spleen weight and longer colon length compared to mice treated with DSS alone. HE-stained colon tissues also exhibited less histologic inflammation in mice treated with $\mathrm{EGb}+$ DSS mice compared to mice treated with DSS alone. The serum levels inflammatory cytokines, KC and TNF- $\alpha$, were also decreased in mice treated with EGb+DSS compared to mice treated with DSS alone. Finally, addition of EGb 761 to TNF- $\alpha$ treated colonic cell line (HT29/c1) decreased secretion of IL-8 in vitro. These results collectively suggest that EGb 761 abates induction of colitis in DSS-induced model of colitis in mice.
\end{abstract}

Key Words: Gingko, Colitis, Dextran sulfate sodium, TNF- $\alpha, \mathrm{KC}$

\section{INTRODUCTION}

Ulcerative colitis (UC) is a serious gastrointestinal tract disease characterized by recurrent chronic inflammation and mucosal damage of the gastrointestinal tract. Patients

\footnotetext{
* Received: November 24, 2014 / Accepted: December 22, 2014

${ }^{\dagger}$ Corresponding author: Bae Dong Jung. College of Veterinary Medicine \& Institute of Veterinary Science, Kangwon National University, Chuncheon, Gangwon-do 200-701, Korea.

Tel: +82-33-250-8674, Fax: +82-33-244-2367

e-mail: bdjung@kangwon.ac.kr

(T) The Korean Society for Biomedical Laboratory Sciences. All rights reserved.
}

with UC exhibit a myriad of clinical symptoms including diarrhea, bloody stool, weight loss, anemia and abdominal pain (Hanauer, 2006). However, the etiology and pathophysiology of this debilitating disease remains unclear. Although no definitive cause is known for UC, various factors including environmental, genetic, lifestyle and immunological dysfunction are generally considered to be contributing factors (Sands, 2007). From a clinical perspective, the main sign of UC is inflammation of the intestine. Thus the elucidation of the inflammatory pathway has offered insights into potential therapeutic strategies for UC (Strober et al., 2007; O'Connor et al., 2010). In UC, induction 
of NF- $\mathrm{KB}$ is a key transcription factor which leads to the production of pro-inflammatory cytokines such as TNF- $\alpha$, IL-6 and IL-1 $\beta$ (Mizoguchi et al., 2002; Pizarro and Cominelli, 2007; Mudter et al., 2008). In addition, Th17 cytokines such as IL-17 and IL-23 have been major contributing factors in UC (Hue et al., 2006; Yen et al., 2006; Seiderer et al., 2008; Sarra et al., 2010). This increase in pro-inflammatory cytokines induces COX-2, iNOS, myeloperoxidase (MPO) and STAT-3, all of which collectively further enhances colonic inflammation and leads to a concomitant decrease in antioxidant levels. The final outcomes of these molecular events are an increase in immune cell infiltration, especially neutrophils and culminate in epithelial cell damage and disruption of the mucosal barrier (Kucharzik et al., 2001; Buhner et al., 2006; Schulzke et al., 2009).

Since UC predominantly manifests as inflammation of the intestine, anti-inflammatory drugs such as sulfasalazine and 5-aminosalicylic acid are treatments of first choice (Neurath and Finotto, 2009; Mehta et al., 2013). Commonly, these treatments often lose their effectiveness and then the patients are treated with biologics. Anti-TNF- $\alpha$ therapy is the most often used biologic, especially infliximab and adalimumab (Hanauer, 2006). These treatments neutralize TNF- $\alpha$ and thus dampen subsequent inflammatory response. The biologics are frequently used in combination with conventional immunosuppressive drugs. However, the therapeutic benefits of these treatments are limited to alleviation of the inflammation and their complications. In addition, long-term usage result in side effects and high relapse. In many cases, surgical excision of the inflamed area is the last option left to the patient. Surgery phobia and repeated relapses in UC have steered many patients to use complementary and alternative medicine to supplement conventional therapy in hopes of abating clinical symptoms (Head and Jurenka, 2004). Most of these patients have attributed significant benefits with few reported adverse complications (Hilsden et al., 2003). Of the extensive list complementary and alternative medicine used, botanicals comprise the major portion. Plants and other dietary agents have been studied extensively for their therapeutic potential in UC patients (Saxena et al., 2014). A few examples include apple, bilberry, black raspberry, green tea, garlic and ginger.
The proposed beneficial effects of these products are broad and likely due to many factors including scavenging of free radicals, homeostatic regulation of intestinal microflora, activation of $\mathrm{T}$ regulatory cells and most importantly antiinflammatory responses. However, the efficacy and mechanism of these products require further studies in in vitro and in vivo animal models to provide mechanistic insights into their function.

Ginkgo biloba is a tree native to Korea, Japan and China. Extracts from the leaves have been used for half a millennium for traditional medicinal purposes. Purported beneficial effects of Ginkgo biloba led to therapeutic applications in alternative medicine. The predominant pharmacologically active components in Ginkgo biloba are flavonols and terpene trilactones (van Beek and Montoro, 2009; Mohanta et al., 2014). However, the therapeutic effects are not attributed to any one constituent and thus maximal benefit is thought to be achieved using the whole extract (Gertz and Kiefer, 2004; Mahadevan and Park, 2008). Although several commercialized Ginkgo biloba extracts (EGb) exist, the standardized EGb 761 leaf extract is most popular. EGb has been reported to be beneficial in Alzheimer's disease, memory loss, cancer, vascular diseases and oxidative stress (Oyama et al., 1996; DeFeudis and Drieu, 2000; Mahadevan and Park, 2008; Silberstein et al., 2011; Mohanta et al., 2014). The "anti-stress" effects of EGb 761 have been researched most extensively and the results indicate that EGb act mainly as antioxidants and free radical scavengers as well as its influence on apoptosis (Maclennan et al., 2002).

Oral administration of dextran sulfate sodium (DSS) is widely used to make a standardized model of colitis in order to study UC (Okayasu et al., 1990). By directly damaging colonic epithelial barrier and following exposure of the bacteria flora, DSS induces colitis characterized by mucosal infiltration of inflammatory cells, epithelial injury and ulceration. DSS-induced colitis is a reproducible model of large intestinal damage that closely resembles human UC. DSS-colitis can be induced in rats and mice, making this an appropriate model for the study of Gingko. DSS induced colitis in both rats and mice induce a loss of body weight, increase in spleen weight and shortening of the 
colon length, all of which occur in proportion to the extent of colonic damage. Therefore, these parameters have been used extensively for indirect measures of colonic damage in the DSS model. The aim of the present study was to evaluate the efficacy of Ginkgo for treatment of UC. Therefore, we administered DSS and investigated several colitis parameters including mouse weight, spleen weight, and inflammatory cytokines then compared them after treatment of EGb 761.

\section{MATERIALS AND METHODS}

\section{Animal experiments}

Six-week-old female C57BL/6 mice (ORIENT BIO, Korea), weighing approximately $16 \mathrm{~g}$ were used in this study. The mice were housed in a standard 12-h light/dark cycle at room temperature, and had ad libitum access to food and water. This animal study was approved by the Animal Care and Use Committee of Yonsei University at Wonju (\#YWC-120424-1). Chronic colitis was induced by administering 2\% DSS (MW 30,000 45,000, MP Biochemicals, Solon, OH, USA) in the drinking water for 7 days, regular water for 7 days and finally $2 \%$ DSS for an additional 7 days. In a subset of mice, EGb 761 (Dr. Willmar Schwabe Pharmaceuticals, Germany) was diluted in water $(1 \mathrm{mg} / 100 \mu \mathrm{L})$ and orally gavaged daily for the duration of the experiment (i.e., 21 days). Each experimental group consisted of a total of 5 10 mice. All animal experiments were performed twice and the data pooled for analysis. Body weight was assessed daily. Mice were euthanized using carbon dioxide euthanasia. Colon lengths and spleen weights were assessed at time of sacrifice.

\section{Histological analysis}

Colon tissues were excised, washed extensively with cold PBS and preserved in $10 \%$ buffered formalin prior to histologic examination by hematoxylin and eosin staining of $5 \mu \mathrm{m}$ sections. To facilitate examination of the colon, tissue samples were 'Swiss rolled' prior to embedding and sectioning. Colon sections were graded for inflammation using a scale of 0 (no inflammation), +1 (mild increase in inflammatory cells; no mucosal changes), +2 (moderate increase in inflammatory cells; mild scattered proliferation and/or focal loss of crypt architecture), +3 (severe increase in inflammatory cells; diffuse or nearly diffuse proliferation, focally extensive loss of crypt architecture), +4 (complete or nearly complete mucosal destruction).

\section{Cell culture and reagents}

HT29/c1 (human colonic epithelial cell line) cells were cultured in 10\% FBS-DMEM containing $20 \mathrm{mM}$ HEPES, penicillin $(100 \mathrm{U} / \mathrm{ml})$ and streptomycin $(100 \mu \mathrm{g} / \mathrm{mL})$ at $37^{\circ} \mathrm{C}$ in $5 \% \mathrm{CO}_{2}$. All cell culture reagents were purchased from GIBCO BRL Life Technologies (Rockville, MD, USA). HT29/c1 cells were seeded at a density of $2 \times 10^{5}$ cells/well in 6-well plates. After $48 \mathrm{~h}$, cells were treated with varying doses of $\mathrm{EGb}$ and/or recombinant human TNF- $\alpha$ (10 ng/mL) (R\&D Systems). Cell supernatants were harvested $24 \mathrm{~h}$ later, clarified and stored at $-20^{\circ} \mathrm{C}$ until assessed by ELISA.

\section{ELISA}

Serum was collected from euthanized mice and stored at $-20^{\circ} \mathrm{C}$ until assayed by ELISA for TNF- $\alpha$ and KC. For assessment of secreted IL-8 in cell culture supernatants, IL-8 ELISA was used. All ELISA kits were purchased from R\&D Systems.

\section{Data analysis}

Statistical analysis and graphic presentation were performed using GraphPad Prism Version 5.01 software. For mouse experiments, data were analyzed using the nonparametric, Mann-Whitney, two-tailed $t$-test. Differences were considered significant if $P<0.05$. For in vitro IL-8 ELISA results, statistical comparison was performed using the unpaired Student $t$-test. $P$ values of $<0.05$ were considered statistically significant.

\section{RESULTS}

\section{EGb ameliorate effects of inflammation in DSS murine model}

To determine if oral intake of EGb ameliorates DSSinduced colitis in mice, C57BL/6 mice were given $2 \%$ 
(A)

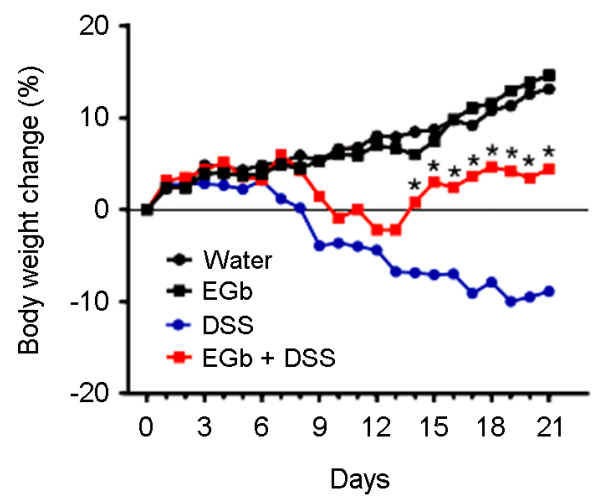

C

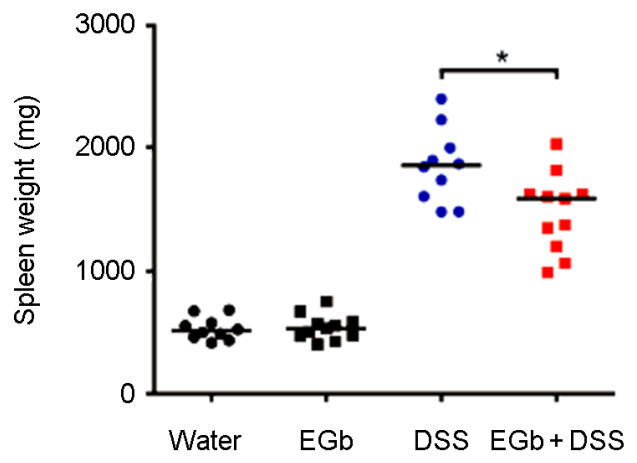

DSS for one week, regular water for one week and $2 \%$ DSS for one week (Fig. 1A). Mice in the experimental group were orally gavaged EGb $(1 \mathrm{mg})$ daily (i.e., EGb+ DSS group). The DSS alone group (i.e., DSS group) were treated identically as above without any EGb. To determine whether EGb alone induced colitis, mice were given EGb for the duration of the experiment (i.e., EGb group). Finally, another group of mice were administered only regular drinking water and served as negative controls (i.e., water group). We found mice in the DSS group exhibited a decrease in body weight beginning at $5 \sim 6$ days post-DSS treatment and this decrease continued during the 21 day experiment. In contrast, mice in the EGb+DSS group initially showed a similar decrease in body weight comparable to the DSS treated group but began recovery at 14 days post-treatment (Fig. 1A). The body weight recovery was statistically significant for up to 21 days. Mice in the EGb treated group showed a nearly identical trend in body weight change comparable to mice in the water group. This result suggests that EGb uptake ameliorated the negative effects
B

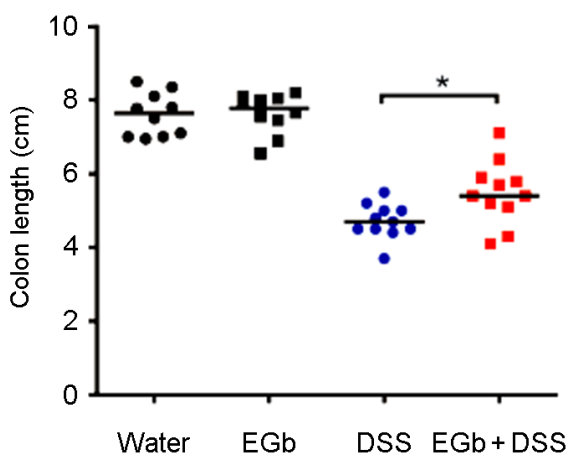

Fig. 1. Clinicopathologic analysis of $\mathrm{C} 57 \mathrm{BL} / 6$ mice treated with DSS and/or EGb. Mice were administered $2 \%$ DSS for 7 days then regular water for 7 days and then DSS for an additional 7 days. EGb 761 (1 mg/dose) was given daily by oral gavage throughout the duration of the experiment (i.e., 21 days). (A) Body weight change. The daily body weight of individual mice was normalized to the starting body weight ( $\mathrm{n}=10 \sim 15$ mice). (B) Colon length. (C) Spleen weight. Bars, median weight. $* P<0.05$. Mann-Whitney, two-tailed $t$-test.

on DSS on body weight.

Shortening of the colon length is used as an indirect measure of colitis severity in the murine DSS model of colitis (Okayasu et al., 1990). The mouse colon shrinks in length during colonic inflammation and mouse colon lengths are used as a parameter for inflammation. The colon lengths were measured at time of sacrifice. We found that DSS treated mice exhibited dramatic shortening of the colon length as expected while the EGb+DSS treated mice showed a statistically significant increased colon length compared to DSS mice (Fig. 1B). EGb mice showed similar colon length compared to the water control group. These results are consistent with the body weight change data and imply that EGb ameliorated DSS colitis. Another often used indirect parameter of colitis severity in the DSS colitis model is increased spleen weight (Okayasu et al., 1990). We found that the spleen weights of EGb+DSS treated mice was lower than that of DSS mice consistent with the results that EGb ameliorate DSS-induced colitis severity (Fig. 1C). 


\section{EGb ameliorates histologic damage of colon in DSS treated mice}

We found that whereas DSS treated mice exhibited extensive inflammation of the colon, the EGb+DSS mice showed a decrease in inflammation of the colon compared to DSS mice (Fig. 2A). EGb mice showed no histologic evidence of inflammation in the colon (Fig. 2B) comparable to the water treated group. In all groups, there was no evidence of inflammation of the small intestine (data not shown).

\section{EGb ameliorates induction of inflammatory cytokines in serum}

The results thus far suggest that EGb ameliorates DSS induced colitis in C57BL/6 mice. We next determined if $\mathrm{EGb}$ also ameliorated induction of systemic inflammatory cytokines. At the end of the 21 day experiment the serum was collected and analyzed for two canonical inflammatory cytokines, $\mathrm{KC}$ and TNF- $\alpha$. Murine $\mathrm{KC}$ is a homologue of human IL- 8 and promotes recruitment of neutrophils. TNF- $\alpha$ is a key inflammatory cytokine produced primarily by macrophages and is involved in initiation of inflam- matory response. We found that both $\mathrm{KC}$ and $\mathrm{TNF}-\alpha$ was elevated in serum of DSS treated mice, whereas EGb+DSS treated mice showed statistically reduced levels of both $\mathrm{KC}$ and TNF- $\alpha$ (Fig. 3).

\section{EGb decreases inflammatory responses in colonic epithelial cell line}

The experimental evidence thus far suggests that EGb uptake reduces DSS-induced colitis in mice. DSS administration induces secretion of TNF- $\alpha$ which can in turn induce secretion of $\mathrm{KC}$ in mice. We determined if $\mathrm{EGb}$ could directly suppress inflammatory responses in epithelial cells in response to TNF- $\alpha$ treatment. HT29/c1 cells, a human colonic epithelial cell line, were treated with TNF- $\alpha+\mathrm{EGb}$ for $24 \mathrm{~h}$ and the secretion of IL- 8 assessed by ELISA. We found that addition of EGb $(1 \mathrm{mg} / \mathrm{mL})$ to TNF- $\alpha$ treated HT29/c1 cells decreased IL-8 levels compared to TNF- $\alpha$ treated cells (Fig. 4). EGb did not exhibit an inhibitory effect at lower doses. There was no evidence of cell toxicity when cells were treated with EGb at $1 \mathrm{mg} / \mathrm{mL}$ but cells treated at higher concentrations of EGb exhibited a loss in cell viability (data not shown). These results suggest that the protective effect of EGb in the DSS-induced colitis in
A
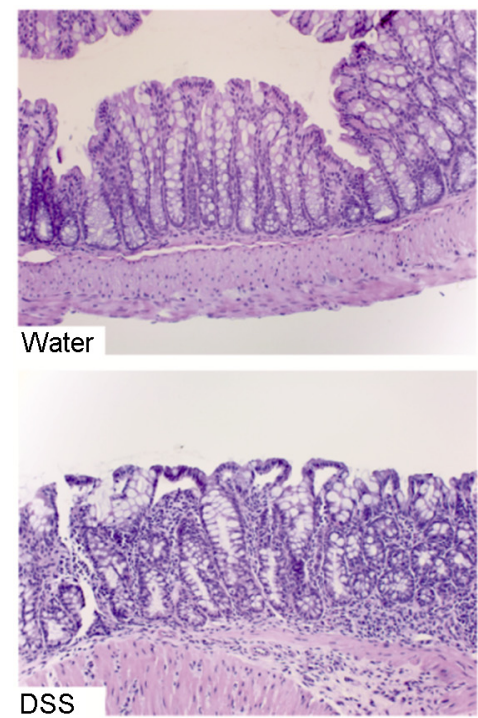

Fig. 2. EGb ameliorates DSS-induced colitis. (A) H\&E-stained tissue sections of the colon at 21 days post-treatment ( $\times 100$ ). (B) Histologic inflammation scores of the colon at day 21. ${ }^{*} P<0.05$. Mann-Whitney, two-tailed $t$-test.
B

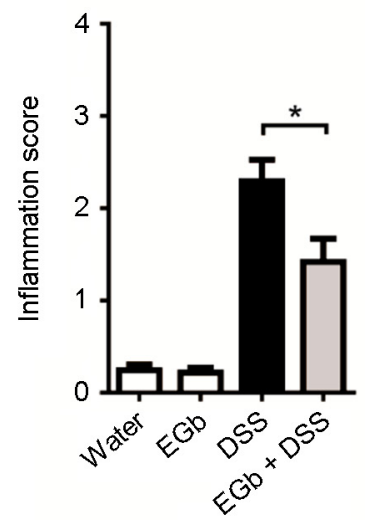


(A)

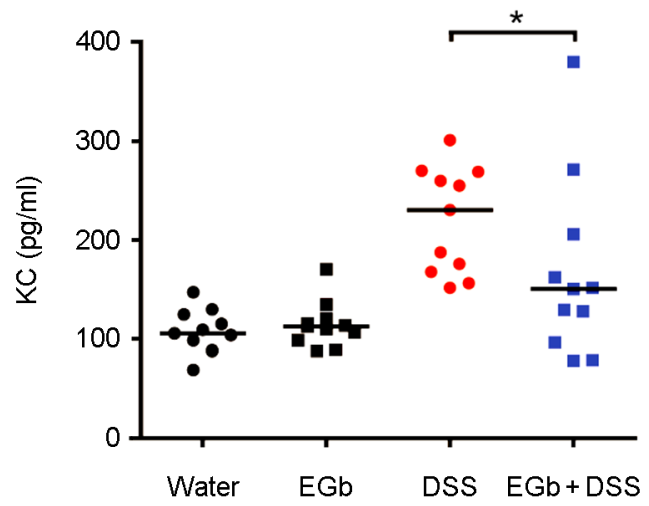

B

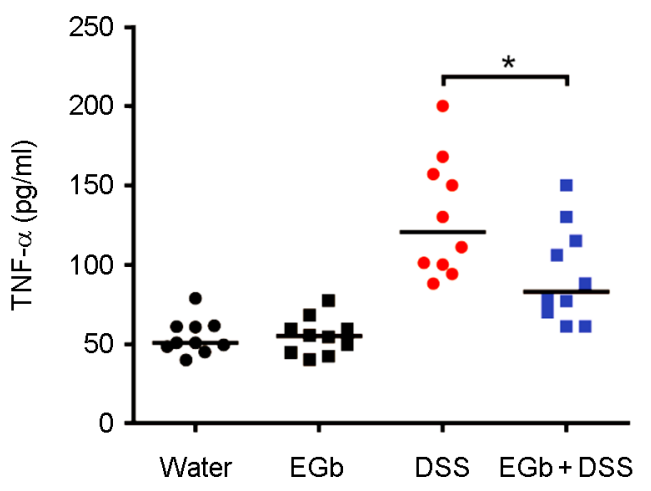

Fig. 3. EGb inhibits induction of serum inflammatory cytokines in DSS-treated mice. C57BL/6 mice were administered EGb and/or DSS for 21 days and levels of inflammatory cytokines analyzed by ELISA. (A) Serum KC levels. (B) Serum TNF- $\alpha$ levels. ${ }^{*} P<0.05$. Bars, median. Mann-Whitney, two-tailed $t$-test.

the murine model may be in part to reduction of the IL-8 homologue, $\mathrm{KC}$.

\section{DISCUSSION}

Although much progress has been made into the treatment of UC, these conventional treatment strategies often induce undesired side effects. Thus many UC patients have turned to alternative therapies to complement existing conventional therapy (Hilsden et al., 2003; Head and Jurenka, 2004). Although the efficacy of Ginkgo biloba extracts in UC patients are still under investigation, in a small study, $33 \%$ of UC patients treated with a commercialized formula of Ginkgo biloba extract (Cedemin) underwent disease remission (Sandberg-Gertzen, 1993). These results offer promise for use of EGb in alleviating UC related symptoms.

There were several studies on testing the efficacy of EGb extract on colitis in rodent models. Similar to our current study, Kotakadi et al., also tested the efficacy of EGb extract on DSS-induced colitis in mice (Kotakadi et al., 2008). In this study, EGb 761 was mixed into the mouse chow so that the average consumption of EGb 761 was estimated to be approximately $0.5 \sim 1 \mathrm{mg}$ per mouse per day. This dose was equivalent to $\sim 58 \mathrm{mg}$ daily for a human which is generally the recommended dose in humans (Koltermann et al., 2007). At this dose, EGb decreased DSS-induced colitis and more importantly caused a statistically significant

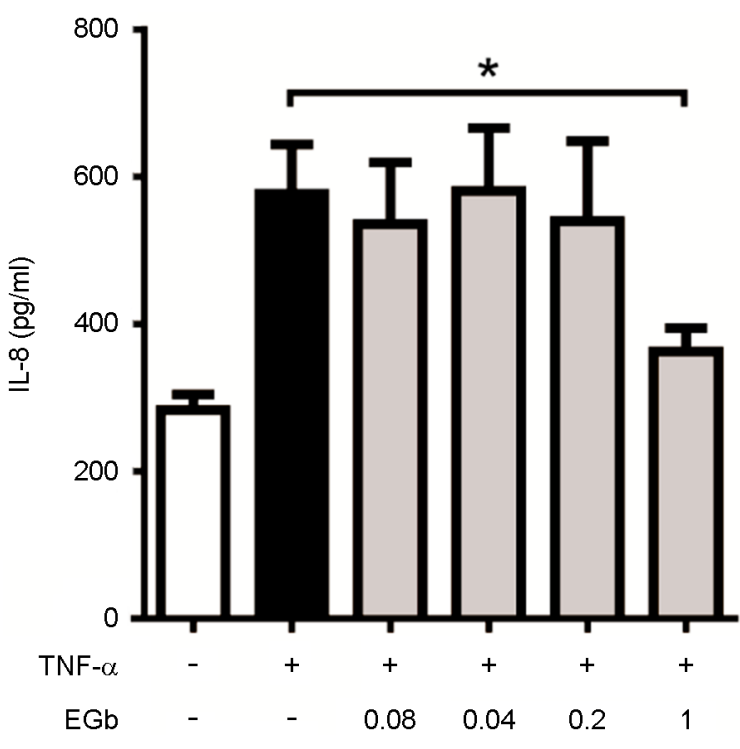

Fig. 4. EGb ameliorates IL-8 secretion in TNF- $\alpha$ treated colonic epithelial cells. HT29/c1 cells were seeded at a density of $2 \times$ $10^{5}$ cells/well in 6-well plates. After $48 \mathrm{~h}$, cells were treated with varying doses of $\mathrm{EGb}$ and/or recombinant human TNF- $\alpha$ (10 ng/ $\mathrm{mL}$ ). Cell supernatants were assessed for IL-8 secretion by ELISA. Data are shown as mean \pm SEM from three independent experiments. $* P<0.05$. Student's $t$-test.

remission of established DSS-induced colitis. Furthermore, the induction of TNF- $\alpha$ in the colonic tissues was decreased. However, serum TNF- $\alpha$ levels was not examined. Of note, in the study by Kotakadi et al., the investigators supplemented the standard diet with double the iron content. The 
dietary iron supplementation enhances DSS-induced colitis in mice (Seril et al., 2002). To our knowledge this is the only study testing the efficacy of EGb in a DSS-colitis model in mice.

Two studies were conducted on rats testing the effect of $\mathrm{EGb}$ on colitis, using acetic acid as colitis inducing agent. In the first study, Mustafa et al., orally gavaged EGb (30 $120 \mathrm{mg} / \mathrm{kg}$ ) for 2 days prior to induction of colitis and then induced colitis using intracolonic instillation of acetic acid (Mustafa et al., 2006). The rats were examined five days later. They found that MPO activity, indicative of neutrophil infiltration, was decreased, as well as TNF- $\alpha$ and IL-1 $\beta$ levels in the colonic tissues. In addition, they found decreased histologic damage of the colon suggesting that EGb may be protective in rats. In the second study, Harputluoglu et al., induced colitis in rats using intracolonic instillation of acetic acid but EGb was administered by intraperitoneal injection prior to induction of colitis (Harputluoglu et al., 2006). They found that histologic colonic damage was slightly decreased but did not reach statistical significance compared to acetic acid treated control rats. The authors concluded that EGb did not significantly affect histopathologic parameters in experimental colitis. Although it is not clear why this discrepancy exist, possible reasons include the source of the EGb extract used, dose of acetic acid and the duration of the experiments. Furthermore, Mustafa et al. administered EGb via oral gavage whereas Harputluoglu et al. administered EGb via intraperitoneal injections. It would appear that oral gavage is more physiologically relevant as $\mathrm{EGb}$ is consumed orally. However, intraperitoneal injection of EGb did protect mice in a LPS-induced sepsis model suggesting that intraperitoneal injections is an effective route of administration (Rhee et al., 2012).

In addition to using acetic acid as a colitis inducing agent in rats, the effects of EGb on colitis was tested using the 2,4,6-trinitrobenzenesulfonic acid (TNBS) colitis model. TNBS is a well characterized hapten that induces chronic colonic inflammation and ulceration in the rat colon (Morris et al., 1989; Neurath et al., 2000). Zhou et al., found that in the TNBS-induced colitis rat model, daily oral gavage of $\mathrm{EGb}(50 \sim 200 \mathrm{mg} / \mathrm{kg})$ for 4 weeks attenuated mRNA expression of TNF- $\alpha$ and IL- 6 in colonic tissues as well as decreased histologic damage (Zhou et al., 2006). In a similar study, Motawi et al., also used the TNBS model in rats, and gave $\mathrm{EGb}(100 \mathrm{mg} / \mathrm{kg})$ via intraperitoneal injection 3 days prior to induction of colitis with TNBS (Motawi et al., 2012). They found decreased levels of MPO, matrix metalloproteases (MMP), nitric oxide (NO) and TNF- $\alpha$ in the colonic tissues as well as decreased histologic damage in the colon.

In our current study, we found that EGb did not have a noticeable benefit on body weight change for up to 13 days post induction of colitis. Starting from day 14, there was a statistical difference in body weight change in EGb+DSS treated mice showing increased body weight change indicative of colonic regeneration. This positive trend remained for the duration of the experiment. Other parameters of colitis, namely colon length and spleen weight, suggested an improvement in colitis in EGb+DSS treated mice compared to DSS treated mice. More importantly, histologic examination showed a decrease in colonic inflammation in $\mathrm{EGb}+\mathrm{DSS}$ treated mice compared to DSS treated mice. The serum levels of the inflammatory cytokines, $\mathrm{KC}$ and TNF- $\alpha$, were also decreased in EGb+DSS treated mice compared to DSS treated mice suggesting that these inflammatory mediators were decreased not only locally in the colonic tissues but decreased in the circulation. To our knowledge, our study is the first to detect decreased $\mathrm{KC}$ and TNF- $\alpha$ levels in the serum of EGb+DSS treated mice. Mice treated with EGb alone were identical to water treated mice in all parameters examined. This is consistent with the notion that EGb is well tolerated even at high concentrations with no deleterious effects (Zimmermann et al., 2002; Gertz and Kiefer, 2004).

Macrophages produce TNF- $\alpha$, the levels of which are often increased in both animal models and UC patients (Rogler and Andus, 1998). TNF- $\alpha$ secreted by macrophages stimulates production of IL- 8 by epithelial cells. IL- 8 is a key mediator of neutrophil recruitment which exacerbates colitis in UC patients. The infiltrated and activated neutrophils represent an important source of reactive oxygen species which can further cause tissue damage. Neutrophils also release proteases that degrade the extracellular matrix. The novel finding in our study is that treatment of TNF- $\alpha$ 
stimulated colonic epithelial cell line (HT29/c1) with EGb exhibited decreased secretion of IL-8 (Schuerer-Maly et al., 1994). The finding that EGb can directly suppress TNF- $\alpha$ induced IL-8 secretion by epithelial cells provides a new aspect of EGb protective effect. Previously, Kotakadi et al. showed that EGb can suppress TNF- $\alpha$ expression in IFN- $\gamma$ stimulated macrophages (Kotakadi et al., 2008). In the same study, the authors demonstrated that apoptosis of CD4+ T cells was increased by EGb treatment. Cheng et. al., showed that EGb inhibited TNF- $\alpha$ secretion in T cells (Cheng et al., 2003). It is possible that in our model system EGb may also be inducing $\mathrm{T}$ cell apoptosis and/or suppression of TNF- $\alpha$ secretion as well as suppressing IL-8 secretion by epithelial cells.

In summary, our study shows that oral administration of EGb 761 in DSS-treated mice dampens colitis. We show for the first time that EGb suppresses IL-8 secretion by epithelial cells. This mechanism as well as the suppression of TNF- $\alpha$ secretion by $\mathrm{T}$ cells and $\mathrm{T}$ cell apoptosis may all play a role in EGb induced suppression of colitis. The diverse mechanism by which EGb 761 exerts its antiinflammatory effect in the colon needs is beginning to be elucidated and warrants further investigation.

\section{Acknowledgements}

We acknowledge the technical assistance of Jaewon Lim and Yoonjung Cho.

\section{REFERENCES}

Buhner S, Buning C, Genschel J, Kling K, Herrmann D, Dignass A, Kuechler I, Krueger S, Schmidt HH, Lochs H. Genetic basis for increased intestinal permeability in families with Crohn's disease: role of CARD15 3020insC mutation? Gut. 2006. 55: 342-347.

Cheng SM, Yang SP, Ho LJ, Tsao TP, Juan TY, Chang DM, Chang

SY, Lai JH. Down-regulation of c-jun N-terminal kinaseactivator protein-1 signaling pathway by Ginkgo biloba extract in human peripheral blood $\mathrm{T}$ cells. Biochem Pharmacol. 2003. 66: 679-689.

DeFeudis FV, Drieu K. Ginkgo biloba extract (EGb 761) and CNS functions: basic studies and clinical applications. Curr Drug Targets. 2000. 1:25-58.
Gertz HJ, Kiefer M. Review about Ginkgo biloba special extract EGb 761 (Ginkgo). Curr Pharm Des. 2004. 10: 261-264.

Hanauer SB. Inflammatory bowel disease: epidemiology, pathogenesis, and therapeutic opportunities. Inflamm Bowel Dis. 2006. 12 Suppl 1: S3-9.

Harputluoglu MM, Demirel U, Yucel N, Karadag N, Temel I, Firat S, Ara C, Aladag M, Karincaoglu M, Hilmioglu F. The effects of Gingko biloba extract on acetic acid-induced colitis in rats. Turk J Gastroenterol. 2006. 17: 177-182.

Head K, Jurenka JS. Inflammatory bowel disease. Part II: Crohn's disease--pathophysiology and conventional and alternative treatment options. Altern Med Rev. 2004. 9: 360-401.

Hilsden RJ, Verhoef MJ, Best A, Pocobelli G. Complementary and alternative medicine use by Canadian patients with inflammatory bowel disease: results from a national survey. Am J Gastroenterol. 2003. 98: 1563-1568.

Hue S, Ahern P, Buonocore S, Kullberg MC, Cua DJ, McKenzie BS, Powrie F, Maloy KJ. Interleukin-23 drives innate and T cell-mediated intestinal inflammation. J Exp Med. 2006. 203: 2473-2483.

Koltermann A, Hartkorn A, Koch E, Furst R, Vollmar AM, Zahler S. Ginkgo biloba extract EGb 761 increases endothelial nitric oxide production in vitro and in vivo. Cell Mol Life Sci. 2007. 64: $1715-1722$

Kotakadi VS, Jin Y, Hofseth AB, Ying L, Cui X, Volate S, Chumanevich A, Wood PA, Price RL, McNeal A, Singh UP, Singh NP, Nagarkatti M, Nagarkatti PS, Matesic LE, Auclair K, Wargovich MJ, Hofseth LJ. Ginkgo biloba extract EGb 761 has anti-inflammatory properties and ameliorates colitis in mice by driving effector $\mathrm{T}$ cell apoptosis. Carcinogenesis. 2008. 29: 1799-1806.

Kucharzik T, Walsh SV, Chen J, Parkos CA, Nusrat A. Neutrophil transmigration in inflammatory bowel disease is associated with differential expression of epithelial intercellular junction proteins. Am J Pathol. 2001. 159: 2001-2009.

Maclennan KM, Darlington CL, Smith PF. The CNS effects of Ginkgo biloba extracts and ginkgolide B. Prog Neurobiol 2002. 67: 235-257.

Mahadevan S, Park Y. Multifaceted therapeutic benefits of Ginkgo biloba L.: chemistry, efficacy, safety, and uses. J Food Sci. 2008. 73: R14-19.

Mehta SJ, Silver AR, Lindsay JO. Review article: strategies for the management of chronic unremitting ulcerative colitis Aliment Pharmacol Ther. 2013. 38: 77-97.

Mizoguchi E, Mizoguchi A, Takedatsu H, Cario E, de Jong YP, 
Ooi CJ, Xavier RJ, Terhorst C, Podolsky DK, Bhan AK. Role of tumor necrosis factor receptor 2 (TNFR2) in colonic epithelial hyperplasia and chronic intestinal inflammation in mice. Gastroenterology. 2002. 122: 134-144.

Mohanta TK, Tamboli Y, Zubaidha PK. Phytochemical and medicinal importance of Ginkgo biloba L. Nat Prod Res. 2014. 28: 746-752.

Morris GP, Beck PL, Herridge MS, Depew WT, Szewczuk MR, Wallace JL. Hapten-induced model of chronic inflammation and ulceration in the rat colon. Gastroenterology. 1989. 96: 795-803.

Motawi TK, Rizk SM, Shehata AH. Effects of curcumin and Ginkgo biloba on matrix metalloproteinases gene expression and other biomarkers of inflammatory bowel disease. J Physiol Biochem. 2012. 68: 529-539.

Mudter J, Amoussina L, Schenk M, Yu J, Brustle A, Weigmann B, Atreya R, Wirtz S, Becker C, Hoffman A, Atreya I, Biesterfeld S, Galle PR, Lehr HA, Rose-John S, Mueller C, Lohoff M, Neurath MF. The transcription factor IFN regulatory factor-4 controls experimental colitis in mice via T cell-derived IL-6. J Clin Invest. 2008. 118: 2415-2426.

Mustafa A, El-Medany A, Hagar HH, El-Medany G. Ginkgo biloba attenuates mucosal damage in a rat model of ulcerative colitis. Pharmacol Res. 2006. 53: 324-330.

Neurath M, Fuss I, Strober W. TNBS-colitis. Int Rev Immunol. 2000. 19: 51-62.

Neurath MF, Finotto S. Translating inflammatory bowel disease research into clinical medicine. Immunity. 2009. 31: 357-361.

O'Connor PM, Lapointe TK, Beck PL, Buret AG. Mechanisms by which inflammation may increase intestinal cancer risk in inflammatory bowel disease. Inflamm Bowel Dis. 2010. 16: 1411-1420.

Okayasu I, Hatakeyama S, Yamada M, Ohkusa T, Inagaki Y, Nakaya R. A novel method in the induction of reliable experimental acute and chronic ulcerative colitis in mice. Gastroenterology. 1990. 98: 694-702.

Oyama Y, Chikahisa L, Ueha T, Kanemaru K, Noda K. Ginkgo biloba extract protects brain neurons against oxidative stress induced by hydrogen peroxide. Brain Res. 1996. 712: 349-352.

Pizarro TT, Cominelli F. Cytokine therapy for Crohn's disease: advances in translational research. Annu Rev Med. 2007. 58: 433-444.

Rhee K-J, Kim H-C, Jung BD. Effect of Ginkgo biloba extract on the survival rate in lipopolysaccharide-induced sepsis model mice. Korean J Vet Serv. 2012. 35: 191-195.
Rogler G, Andus T. Cytokines in inflammatory bowel disease. World J Surg. 1998. 22: 382-389.

Sandberg-Gertzen H. An open trial of Cedemin, a Gingko biloba extract with PAF-antagonistic effects for ulcerative colitis. Am J Gastroenterol. 1993. 88: 615-616.

Sands BE. Inflammatory bowel disease: past, present, and future. J Gastroenterol. 2007. 42: 16-25.

Sarra M, Pallone F, Macdonald TT, Monteleone G. IL-23/IL-17 axis in IBD. Inflamm Bowel Dis. 2010. 16: 1808-1813.

Saxena A, Kaur K, Hegde S, Kalekhan FM, Baliga MS, Fayad R. Dietary agents and phytochemicals in the prevention and treatment of experimental ulcerative colitis. J Tradit Complement Med. 2014. 4: 203-217.

Schuerer-Maly CC, Eckmann L, Kagnoff MF, Falco MT, Maly FE. Colonic epithelial cell lines as a source of interleukin-8: stimulation by inflammatory cytokines and bacterial lipopolysaccharide. Immunology. 1994. 81: 85-91.

Schulzke JD, Ploeger S, Amasheh M, Fromm A, Zeissig S, Troeger H, Richter J, Bojarski C, Schumann M, Fromm M. Epithelial tight junctions in intestinal inflammation. Ann N Y Acad Sci. 2009. 1165: 294-300.

Seiderer J, Elben I, Diegelmann J, Glas J, Stallhofer J, Tillack C, Pfennig S, Jurgens M, Schmechel S, Konrad A, Goke B, Ochsenkuhn T, Muller-Myhsok B, Lohse P, Brand S. Role of the novel Th17 cytokine IL-17F in inflammatory bowel disease (IBD): upregulated colonic IL-17F expression in active Crohn's disease and analysis of the IL17F p.His161Arg polymorphism in IBD. Inflamm Bowel Dis. 2008. 14: 437-445.

Seril DN, Liao J, Ho KL, Warsi A, Yang CS, Yang GY. Dietary iron supplementation enhances DSS-induced colitis and associated colorectal carcinoma development in mice. Dig Dis Sci. 2002. 47: 1266-1278.

Silberstein RB, Pipingas A, Song J, Camfield DA, Nathan PJ, Stough C. Examining brain-cognition effects of ginkgo biloba extract: brain activation in the left temporal and left prefrontal cortex in an object working memory task. Evid Based Complement Alternat Med. 2011. 2011: 164139.

Strober W, Fuss I, Mannon P. The fundamental basis of inflammatory bowel disease. J Clin Invest. 2007. 117: 514-521.

van Beek TA, Montoro P. Chemical analysis and quality control of Ginkgo biloba leaves, extracts, and phytopharmaceuticals. J Chromatogr A. 2009. 1216: 2002-2032.

Yen D, Cheung J, Scheerens H, Poulet F, McClanahan T, McKenzie B, Kleinschek MA, Owyang A, Mattson J, Blumenschein W, Murphy E, Sathe M, Cua DJ, Kastelein RA, Rennick D. 
IL-23 is essential for T cell-mediated colitis and promotes inflammation via IL-17 and IL-6. J Clin Invest. 2006. 116: 1310-1316

Zhou YH, Yu JP, Liu YF, Teng XJ, Ming M, Lv P, An P, Liu SQ, Yu HG. Effects of Ginkgo biloba extract on inflammatory mediators (SOD, MDA, TNF- $\alpha$, NF-kBp65, IL-6) in TNBS- induced colitis in rats. Mediators Inflamm. 2006. 2006: 92642.

Zimmermann M, Colciaghi F, Cattabeni F, Di Luca M. Ginkgo biloba extract: from molecular mechanisms to the treatment of Alzhelmer's disease. Cell Mol Biol (Noisy-le-grand). 2002. 48: 613-623. 